\title{
INVESTIGATION OF THE STUDENTS MOTIVATION FOR LEARNING ENGLISH AS SECONDARY LANGUAGE: AN EMPIRICAL STUDY
} \author{
University of Sindh, \\ Sindh, Pakistan

\section{Sohail Ahmed} \\ University of Sindh, \\ Sindh, Pakistan

\section{Majid Hashim} \\ Scholar, \\ Sukkur IBA, \\ Sindh, Pakistan
}

Abdul Rahim Chandio

Scholar, Department of Public Administration,

Email: abdulrahim.chandio@scholars.usindh.edu.pk

Scholar, Department of Public Administration,

\begin{abstract}
For learning any language, motivation plays a vital role. This study aims to investigate collegiate students' predictive motivational factors toward students' attitude toward learning English as secondary language. This is a cross-sectional study in which questionnaire was adapted from the existing literature for data collection. For this quantitative study data were collected from two government degree colleges of Larkana. Total 400 questionnaires were randomly distributed among intermediate students both boys and girls, out of that 247 were returned. Data were analyzed using statistical packages for social sciences (SPSS) version 24. Initially, data were cleaned by identifying missing values and outliers. Study hypotheses were examined using Multiple Regression Analysis (MRA). The findings of this study revealed that instrumental motivation and parental encouragement (independent variables) have positive and significant relationship with attitude toward learning English. However, one variable i.e. integrative motivation was not found as a significant and positive predictor of the dependent variable. Like any study, this study also possesses few limitations, such as sample size, time horizon, and context of the study. In the end, future directions are given for further exploration.
\end{abstract}




\section{KEYWORDS}

Students' motivation, Language learning, Parental encouragement

\section{INTRODUCTION}

Motivational learning plays a significant service in the learning of language (Dörnyei, 1994; Gardner \& Lambert, 1959). Learner's orientation can enhance motivational approach to assist to attain the learning's goal as a secondary language. According to Gardner (1972), motivation has been categorized into two types, for instance, instrumental orientation, and integrative orientation. Integrative motivation implies the positive attitude and sentiment regarding the population of an intended language and utilizes the target language in order to maintain communication with the speakers of native.

Instrumental motivation assists to achieve social rewards and economic advantages via the miracle of secondary language, thus learning of the language is more fruitful and reason-oriented. The behaviors of family members, learning attitudes, educational levels, lifestyles, and education methods of parents and hopes for the education of children and additional aspects impact the interest of the student's learning that maintain its influence in the learning process of children Chen, (2010). Family plays the role of the cradle for young children and the primary group becomes the earlier teacher. In which parents and older siblings provide the primary socialization and perform the responsibility to be the first teacher. The words of parents influence the children directly in their way to understand the things in an easy manner. For the growth of health of a child, family environment plays a significant role. Students achieve the primary environment from his family that helps him to grow. Henceforth, for the healthy growth of children family environment is crucial.

Parents' desire is preferred by children in his learning motivational approach (Usher and Kober, 2012). The desires of parents concerning the learning of their children provide a massive service role on the learning motivation of children; particularly external influences emerge among the young learners for their positive learning motivations (Gottfried, Fleming, \& Gottfried, 1994). According to Honig (1979), for the young children parental role is very impressive. Involvement of parents in the learning of children can enhance the academic achievement of students. However, according to the authors' viewpoint, there are a small number of publications in which debate of parental encouragement regarding their stimulating the children's learning motivation 
foreign languages as the English language in Pakistan at its primary level. In this regard, no studies have been found concerning the dilemma, in the researchers' consideration that the study like this could facilitate to meet the major crisis of the motivational fluctuation to learn English as a secondary language among the collegiate students of Larkana District.

In this study, attention has been paid concerning the students' integrative as well as instrumental motivation and the degree of student's encouraging estimation of their parents, to find out the attitude of students toward English language learning. The survey of the study was carried out among the students of the first year and second year at two government degree colleges of Larkana. Both groups of students i.e. pre-medical and pre-engineering were included in this survey.

\section{Theoretical Framework}

In Gardner's Social Educational Model of Second, Language Acquisition there are a number of factors that assist the students' motivation for learning the foreign language. Likely, a socio-educational model of Gardner (1972) and Gardner, \& Lambert, (1972), argued that inspiration of foreign language's learning developed due to the number of constructs in which interrelationships have been maintained. He paid attention to the classroom of foreign languages. There is the motivational test has been designed with its 130 items by Gardner (1985) that encompass the instrumental orientation, parental encouragement, integrative orientation and others. Such an instrument was titled as the attitude motivation test battery (AMTB). Moreover, goal setting gives birth to an indispensable stimulus to enhance and lead motivational approach for learning the language (Gardner, 1985). He categorized two main motivational orientations. One is the Integrative orientation which refers to the learners' aspiration to contribute to the culture of the target language, to assimilate and hold their life to a new community via utilization of the target language. When a learner possesses the motivation to learn they would like the other group of language for communication and keep a positive outlook in the process of the language learning (Masgoret \& Gardner, 2003).Instrumental orientation denotes the learning of the target language with a concrete reason, for instance, a language requirement, or appreciation from others. It is the mode of learning of a second language (L2) when Student's disinterest to communicate in the target language with the members. Instrumental motivation has been defined by Dornyei, Csizér, and Németh (2006) as the learner stimulus to acquire the 
language through the uses of the languages for utilitarian objectives (Gardner, 1985). In 1972, Gardner and Lambert reported that instrumental motivation focuses on considering the functional reasons for learning the target language like getting a high-salary job, or higher rank.

Based on Gardner's Socio-Educational Model of Second Language Acquisition and the research issues discussed in this paper, there is another important variable that affects students learning motivation, i.e., parental encouragement for learning the language. Gardner and his colleagues carried out studies for over forty years of parental encouragement. Gardner demonstrated that parents can influence the children to do well in the class when learning a language, and express their negative or positive attitudes toward the people or group that speak the language by encouraging them or using open questions (Gardner, 2010). He wrote that parents may see the benefits of learning a language - e.g., getting a good grade, getting into a college or university -and directly pass the sentiment on to their children. All types of parental involvement do not have a positive relationship with the learning motivation of students and illustrated for more studies probing diverse features of parental involvement and dissimilar elements of student's motivational attainment (Grolnick and Slowiaczek, 1994).

Accordingly, one study of this topic was university students' learning motivation affected by their family backgrounds such as family structure, their functions, cultural values and other psychological factors like selfdetermination (Lumsden, 1994). Further, researchers showed that the parents and home environment played a significant role in students' motivation. They were an important factor in shaping the students' attitudes toward learning the language. Lumsden, also noted that children from homes that encouraged a sense of self-worth, competence, autonomy, and self-efficacy were more likely to accept the challenges involved in learning difficult material. Gottfried, Fleming, and Gottfried (1994) supported this trend and emphasized that parental encouragement of children's learning was a causal influence on their motivation and achievement. Accordingly, parents encourage children's persistence in their study and effort to achieve good results and their curiosity and exploration in specific subject areas. For this study, a research model is based on Gardner's Socio-Educational Model of Second Language Acquisition. 


\section{HYPOTHESES}

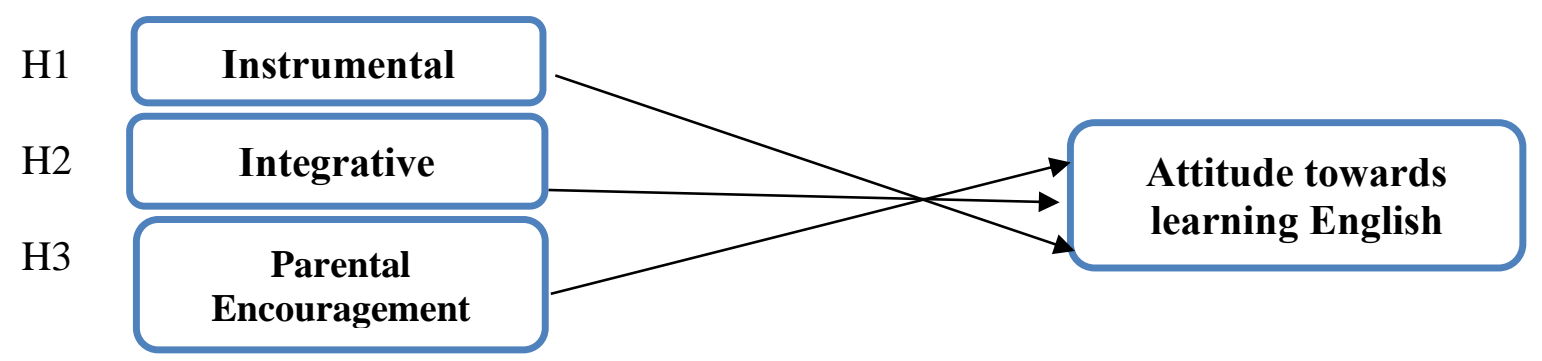

Figure 1: Framework of Students motivation for English learning

Based on the above framework following hypotheses were formulated for examination.

H1: There is a significant and positive relationship between instrumental motivation and students' attitude toward learning English.

$\mathrm{H} 2$ : There is a significant and positive relationship between integrative motivation and students' attitude toward learning English.

H3: There is a significant and positive relationship between parental encouragement and students' attitude toward learning English.

\section{RESEARCH METHODOLOGY}

This study is based on positivism philosophy, in which deductive approach and quantitative methods applied. This is a cross-sectional study, followed by survey-based strategy. Moreover, a structured measurement instrument was adapted from the domain literature. However, this method already has been used by other domain researchers like (Barker, 1998; Crookes et al., 1991; Dörnyei, Z, 1994; Gardner, 1985; Ushioda, E, 2001).

The population is the large-scale sampling as a whole. The population is a set of all elements in which whole targeted population can be represented (Gilbert, 2001). According to Hussey and Hussey, (1997) sample is necessary for empirical study which is based on positivism approach. In this study, the instructions of Krejcie and Morgan (1970) were followed for sampling. The study population consists of intermediate students of two government degree college Larkana, District Larkana. According to Directorate of college Education Larkana, Government of Sindh, the total enrolled intermediate students at government Degree College of boys and Degree College of girls are 550 estimated. 
Following the suggestions of Krejcie and Morgan, (1970) the sample size required for this study is 226. For this study, researchers distributed 200 questionnaires randomly at each college, out of that $247(61.75 \%)$ were returned. While cleaning the data $6(2.42 \%)$ missing values and $5(2.02 \%)$ outliers were identified. All the samples containing missing values and outliers were removed from the sample, as below 5\% does not cause problems with results (Tabachnick and Fidell2007, p-63). In this way, the final sample for data analysis was236. This sample size is in line with Krejcie and Morgan (1970).

The personal visit was maintained in order to distribute the questionnaires to the participant directly. The Researcher used (SPSS, version. 24) for the analysis of data. In this way, data cleaning and descriptive tests were conducted. Moreover, Multiple Regression Analysis (MRA)and Pearson's Correlation were used to examine the hypotheses.

\section{Instruments}

The researcher adapted questionnaire items from the existing studies. However, all the items were measured using five points Likert scale ( $1=$ strongly disagree, $2=$ Disagree, $3=$ Neutral, $4=$ Agree, $5=$ strongly agree). The questionnaire is comprised of two major parts: the first part consists of items about the students' background information (e.g. gender, age, marital status, and group). The second part of the questionnaire is consisting of questions about the study constructs students' motivation instrumental and integrative, parental encouragement and attitude toward learning English.

\section{DATA ANALYSIS \& RESULTS}

Highly the reliable results of the scales in the existing study were found, as pointed out by Cronbach 's $\alpha$ (.871), which highlights the internal consistency of the various scales high that incorporated in the questionnaire of the prevailing survey.

\section{Table 1}

Overall Reliability

\begin{tabular}{cccc}
\hline No of Items & Total Samples & $\begin{array}{c}\text { Cronbach's alpha } \\
(\boldsymbol{\alpha})\end{array}$ & Type \\
\hline 20 & 236 & .893 & High Reliability \\
\hline
\end{tabular}


Pakistan Journal of Educational Research, Vol 2, Issue 1 (2019)

Investigation of the ...

However, the reliability of individual scales differed from each other. Table 2 presents the individual reliability of the constructs.

Table 2

Individual factor reliability

\begin{tabular}{|c|c|c|c|}
\hline Construct & Items & $\begin{array}{l}\text { Cronbach's alpha } \\
(\alpha)\end{array}$ & Type \\
\hline ATLE & 5 & .823 & $\begin{array}{l}\text { High } \\
\text { Reliability }\end{array}$ \\
\hline Instrumental & 5 & .785 & $\begin{array}{l}\text { High } \\
\text { Reliability }\end{array}$ \\
\hline Integrative & 5 & .739 & $\begin{array}{l}\text { High } \\
\text { Reliability }\end{array}$ \\
\hline $\begin{array}{l}\text { Parental } \\
\text { encouragement }\end{array}$ & 5 & .831 & $\begin{array}{l}\text { High } \\
\text { Reliability }\end{array}$ \\
\hline
\end{tabular}

\section{Demographic Characteristics}

The respondent's characteristics for instance gender, age, marital status, and the group were asked in the questionnaire. Table 3 shows the demographic characteristics of the study participants.

Table 3

Demographic characteristics

\begin{tabular}{llll}
\hline Variables & Description & Frequency & Percentage \\
\hline Gender & Male & 138 & 58.5 \\
& Female & 98 & 41.5 \\
Age & $15-17$ & 109 & 46.2 \\
& $18-20$ & 116 & 49.1 \\
\multirow{4}{*}{ Marital Status } & Above 20 & 11 & 4.7 \\
Group & Single & 221 & 93.7 \\
& Parried & 15 & 6.3 \\
& Pre- Medical & 132 & 56 \\
\hline
\end{tabular}

\section{Descriptive statistics of the study variables}

For the research, the transformation of the data was carried out to making it easy to comprehend and better interpretation of the matter (Zikmund, 2002; Neuman, 2013). 
Means, frequencies and standard deviations of the variables have been encompassed by this study which has been driven to present the characteristics of the sample. Outstandingly, items of every latent construct of this study are measured on the score of ' 5 ' of five-point Likert scale which representing the strong agreement and another indicates the strong disagreement with nondemographic questions in the questionnaire survey. All items' means and standard deviation are given in Table 4. The values and means of the all given items reveal an effective agreement among respondents with each statement which were utilized in order to measure the questionnaire survey.

Table 4

Descriptive statistics

\begin{tabular}{llccc}
\hline Construct & Items & N & Mean & $\begin{array}{c}\text { Std. } \\
\text { Deviation }\end{array}$ \\
\hline ATLE & ATLE1 & 236 & 3.24 & 1.32 \\
& ATLE2 & 236 & 3.13 & 1.12 \\
& ATLE3 & 236 & 3.31 & 1.13 \\
& ATLE4 & 236 & 3.39 & 1.17 \\
INST & ATLE5 & 236 & 4.14 & 1.19 \\
& INST1 & 236 & 3.34 & 1.31 \\
& INST2 & 236 & 4.33 & 1.16 \\
& INST3 & 236 & 3.43 & 1.27 \\
INTG & INST4 & 236 & 2.96 & 1.24 \\
& INST5 & 236 & 3.27 & 1.11 \\
& INTG1 & 236 & 3.26 & 1.09 \\
& INTG2 & 236 & 2.83 & 1.17 \\
PREC & INTG3 & 236 & 3.19 & 1.24 \\
& INTG4 & 236 & 4.73 & 1.32 \\
& INTG5 & 236 & 3.29 & 1.27 \\
& PREC1 & 236 & 3.31 & 1.13 \\
& PREC2 & 236 & 4.42 & 1.02 \\
& PREC3 & 236 & 3.21 & 1.15 \\
& PREC4 & 236 & 3.12 & 1.20 \\
\hline
\end{tabular}

Pearson's correlations between constructs

Linearity in the data was tested with the Bivariate Pearson's correlations. Significant correlations between the scales were ascertained at two levels in 
such a way $p=0.05$ and $p=0.01$ It is an essential part of the preliminary analysis to know the level of correlation in data and to figure out if there is any departure from the linearity that might affect the correlations (Field, 2006).

Results of Pearson's correlation revealed that all factors instrumental (INST), integrative (INTG), and parental encouragement (PREC) are significantly and positively correlated with attitude toward learning English (ATLE).

Table 5: $\quad$ Pearson's Correlation

\begin{tabular}{lcccc}
\hline Variables & ATLE & INST & INTG & PREC \\
\hline ATLE & 1 & & & \\
\hline INST & $.510^{* *}$ & 1 & & \\
\hline INTG & $.464^{* *}$ & .161 & 1 & \\
\hline PREC & $.538^{* *}$ & $.209^{*}$ & .137 & 1 \\
\hline **. Correlation is significant at 0.01 (2-tailed) & & \\
*. Correlation is significant at 0.05 (2-tailed) &
\end{tabular}

Note: ATLE =Attitude toward learning English; INST = Instrumental; INTG = Integrative, $\mathrm{PREC}=$ Parental encouragement

\section{Multiple regression analysis}

Besides the correlation between the main research variable, it is important to access the predictive relation between variables. The fact that correlation does not assurance causality, the researcher examined the coefficient of a dependent variable through multiple regression tests. Based on the multiple regression analysis, the research hypotheses were tested from the standardized multiple regression analysis estimates. The findings showed that parental encouragement (PREC) and instrumental motivation (INST) have contributed to the dependent variable attitude toward learning English significantly. However, integrative (INTG) has not contributed to the dependent variable. The test results are present in below table.

Table 6

Multiple Regression Analysis

\begin{tabular}{lccc}
\hline \multicolumn{1}{c}{ Variables } & B & t-value & p-value \\
\hline Instrumental & .217 & 3.315 & .001 \\
Integrative & .047 & .849 & .363 \\
Parental Encouragement & .578 & 7.316 & .000
\end{tabular}




\section{$\mathbf{R}^{2}$}

Adjusted R ${ }^{2}$

F value
.634

.621

71.318

Note: Dependent variable: Attitude toward learning English

\section{DISCUSSION}

The researchers found that the collegiate students' perception of parental encouragement was relatively high. Parental encouragement is another very important factor in students' learning. Parents want their children to succeed and so always use encouragement and positive words as well as supportive action to inspire their children to make improvements. They use their love and cheer their children to try the best to study. Even when they show the bad performance, they offer encouragement and support as well. Students are more likely to achieve their full potential when their parents actively encourage them to explore their interests. The results of the students of the government degree colleges of Larkana showed that both students (e.g. boys and girls) are effectively motivated to learn the English language as a secondary language.

The study presents English as the secondary language among the Pakistani students in order to achieve the utilitarian goals that are concerned to selfesteem and advancement, either it gives an immediate, or benefit for the longer term. Though there is high integrative motivation, particularly in this way to the appreciation for English literature and creating interest to read one's own sake and travel of future, at some extent instrumental motivation is stronger rather than integrative motivation.

Noels, (2001), and Ryan, (2009) argue that it is the fact regarding the instrumental motivation which is highly consistent with the previous record of studies on extrinsic motivation among tertiary students of to learn in English as the secondary language and to learn English language as the foreign language for the purpose of the outside the native communicative source.

The existing study is limited in sample size $(\mathrm{N}=236)$ taken from two government degree colleges of Larkana. The prevailing study does not encompass the general population. Additionally, the existing study is in the quantitative nature. It is recommended to be better to include the qualitative aspect as well which was not made part of the study due to the crisis of time of researcher. Besides this, it is referred to adopt the longitudinal studies on the 
foreign language in Pakistan. However, it is a dire need to adhere the systematic study regarding the teachers' point of view on the anxiety of language in Pakistan.

\section{RECOMMENDATIONS}

The research was conducted only with intermediate students of the two government degree colleges of Larkana. In this way, findings cannot be generalized in another context. Therefore, a primary recommendation for future research is to conduct larger studies in terms of both school levels and additional colleges, both governmental and private in Pakistan. Also, since the current study sought to measure only parental encouragement along with instrumental and integrative motivation effect on the motivational level of the student's language learning, more tests will be needed to verify how parental encouragement impacts on English learning attitude. Lastly, additional research is necessary concerning the academic achievement, ethnic heritage-related learning motivation, and parental involvement.

\section{REFERENCES}

Chen, Z. (2010). The Influence and Suggestion of Family Education to Individual, Retrieved from http://wenku.baidu.com/view/df6a043c0912a21614792915.html

Crookes, G., \& Schmidt, R. W. (1991). Motivation: Reopening the research agenda. Language learning, 41(4), 469-512.

Dörnyei, Z. (1994). Motivation and motivating in the foreign language classroom. The modern language journal, 78(3), 273-284.

Dörnyei, Z. (2000a) Motivation in action: Towards a process-oriented conceptualization of student motivation. British Journal of Educational Psychology, Vol.70, pp. 519-538.

Dörnyei, Z., \&Ottó, I. (1998) Motivation in action: A process model of L2 motivation. Working Papers in Applied Linguistics (Thames Valley University London), Vol.4, pp. 43-69.

Dörnyei, Z., Csizér, K., \&Németh, N. (2006). Motivation, language attitudes and globalisation: A Hungarian perspective. Multilingual Matters.

Gardner, R. C. (1985). Social psychology and second language learning: The role of attitudes and motivation. Arnold.

Gardner, R. C., \& Lambert, W. E. (1959). Motivational variables in second-language acquisition. Canadian Journal of Experimental Psychology, 13, 266. 
Gardner, R. C., \& Lambert, W. E. (1972). Attitudes and Motivation in Second Language Learning.

Gottfried, A. E., Fleming, J. S., \& Gottfried, A. W. (1994). Role of parental motivational practices in children's academic intrinsic motivation and achievement. Journal of Educational Psychology, 86(1), 104.

Grolnick, W. S., \& Slowiaczek, M. L. (1994). Parents' involvement in children's schooling: A multidimensional conceptualization and motivational model. Child development, 65(1), 237-252.

Honig, A. S., \& National Association of Child Education. (1979). Parent involvement in early childhood education (Vol. 1934). Washington, DC: National Association for the Education of Young Children.

Hussey, J., \& Hussey, R. (1997). Business research.

Krejcie, R. V., \& Morgan, D. W. (1970). Determining sample size for research activities. Educational and psychological measurement, 30(3), 607-610.

Lumsden, L. S. (1994). Student Motivation to Learn. ERIC Digest, Number 92.

Masgoret, A. M., \& Gardner, R. C. (2003). Attitudes, motivation, and second language learning: a meta-analysis of studies conducted by Gardner and associates. Language learning, 53(1), 123-163.

Noels, K. A. (2001). New orientations in language learning motivation: Towards a model of intrinsic, extrinsic, and integrative orientations and motivation. Motivation and second language acquisition, 23, 43-68.

Ryan, S. (2009). Self and identity in L2 motivation in Japan: The ideal L2 self and Japanese learners of English. Motivation, language identity and the L2 self, 120-143.

Tabachnick, B. G., \&Fidell, L. S. (2007). Experimental designs using ANOVA. Thomson /Brooks/Cole.

Usher, A., \&Kober, N. (2012). 4. What Roles Do Parent Involvement, Family Background,and Culture Play in Student Motivation? Center on Education policy.

Zikmund, W. G., \& d'Amico, M. (2002). Effective marketing: Creating and Keeping customers in an e-commerce world. South-Western. 